\title{
IQ 532 Micropulse green laser treatment for refractory chronic central serous retinopathy
}

\author{
Fawwaz A1 Mamoori ${ }^{1 *}$ \\ ${ }^{1}$ Medical Retina Department, Eye Specialty Hospital, Amman
}

\section{Introduction}

Central serous chorioretinopathy (CSCR) is an idiopathic disorder characterized by a localized serous detachment of the sensory retina at the macula secondary to leakage from the choriocapillaris through focal, or less commonly diffuse, hyperpermeable RPE defects. CSCR typically affects one eye of a young or middle-aged Caucasian man; women with CSCR tend to be older. Imperfectly defined additional risk factors include psychological stress, type A personality, steroid administration, Cushing syndrome, systemic lupus erythematosus and pregnancy. The disease in acute phase, is characterized by neurosensory detachment with subretinal fluid that spontaneously resolved with no treatment. But if it becomes chronic (CSCR), it can result in permanent vision loss with extensive RPE atrophy [1-4].

Intravitreal Anti VEGF has been advocated by some as a possible treatment option in such cases of persistent CSR. Several small case series have reported significant reductions in central macular thickness and improvements in visual acuity in CSR patients treated with intravitreal anti VEGF injections, the mechanism of action is upregulation of tight junctions between endothelial cells and reduction of vascular fenestrations. A study by Ji Won Lim, MD, and colleagues suggested that VEGF levels in the aqueous humor of patients with chronic CSCR may be elevated compared to normal eyes, but the problem with Anti VEGF injection is the recurrence of subretinal fluid, the need for multiple injections and it is not effective in all chronic CSR cases.

Conventional laser can be used for the extrafoveal leakage areas but it is difficult to apply for subfoveal or juxtafoveal leak due to the risk of scotoma, contrast sensitivity loss, retinal distortion and choroidal neovascularization $(\mathrm{CNV})$.

Photodynamic Therapy (PDT) is one of the options for chronic CSR with juxtafoveal and subfoveal leakage. however, PDT may associated with RPE atrophy, scotoma and CNV.

The IQ 532 Micropulse laser (Iridex CA, USA) is a solid state laser, in which the laser energy is delivered in short pulses. The whole pulse duration is fractionated into 100 micropulses, with duration on time will be $0.1-0.3 \mathrm{~ms}$ for $5-15 \%$ duty cycle, respectively, This will make a non-visible reaction that detected only on the microscopic level, that will be effective to produce RPE photo stimulatory effect without harming the inner retina that exposed to thermal photocoagulation damage in conventional laser, which makes a micropulse laser a very good ,effective and safe option for treatment of chronic CSR cases.

The mechanism of micropulse in chronic CSR is to targeting RPE cells and stimulating them to pump out the excess subretinal fluid [5-16].

\section{Aim and objective}

To assess the efficacy and safety of micropulse $532 \mathrm{~nm}$ green laser in the treatment of refractory nonresolving central serous chorioretinopathy (CSC) cases.

\section{Methods}

The study included a retrospective review of 2 cases of chronic nonresolving CSR that lasting more than 5 months. All the cases were subjected to detailed ophthalmic examination and imaging with fluorescein angiography and swept source OCT (TRITON -TOPCON machine). All the cases were received multiple anti VEGF injections (more than 3 injections) with no improvement.

We decided to treat those resistant cases by using IQ $532 \mathrm{~nm}$ subthreshold micropulse laser treatment. The settings were individualized for each case accordingly. We initially started with (power titration) which defined as the power that gives just a visible reaction on the non-edematous retina about two disc diameters from the center of the fovea. Then we gradually increasing the power by increment of $10 \mathrm{~mW}$, moving to a new area each time, until barely visible reaction is seen. After that we switched the mode to micropulse with doubling or tripling the power, using 200um spot size, pulse duration $300 \mathrm{~ms}$ ( $15 \%$ duty cycle). We applied the laser to the whole leakage area using $7 \mathrm{x} 7$ grid pattern with zero spacing.

The eyes were followed up after 2 weeks and 4weeks using swept source OCT. All the cases had showed an improvement in BCVA, contrast sensitivity and reduction in subretinal fluid height and macular thickness on OCT.

\section{Case 1}

50 years old male had a history chronic asthma with chronic use of steroid medications, presented with decrease vision in the right eye (20/200) of more than 7 months duration, the patient had received 4 injections of Ranibizumab ( Lucentis ,Novartis)in the right eye with no improvement, the fundus examination showed foveal detachment on the right eye, the angiogram showed a small leakage areas near to the center, the swept source OCT showed a huge neurosensory detachment with subfoveal RPE detachment (Figure 1).

Correspondence to: Fawwaz al mamoori, Medical Retina Department, Eye Specialty Hospital, Amman, E-mail: fawazalmamoori@gmail.com

Received: April 18, 2017; Accepted: May 15, 2017; Published: May 18, 2017 

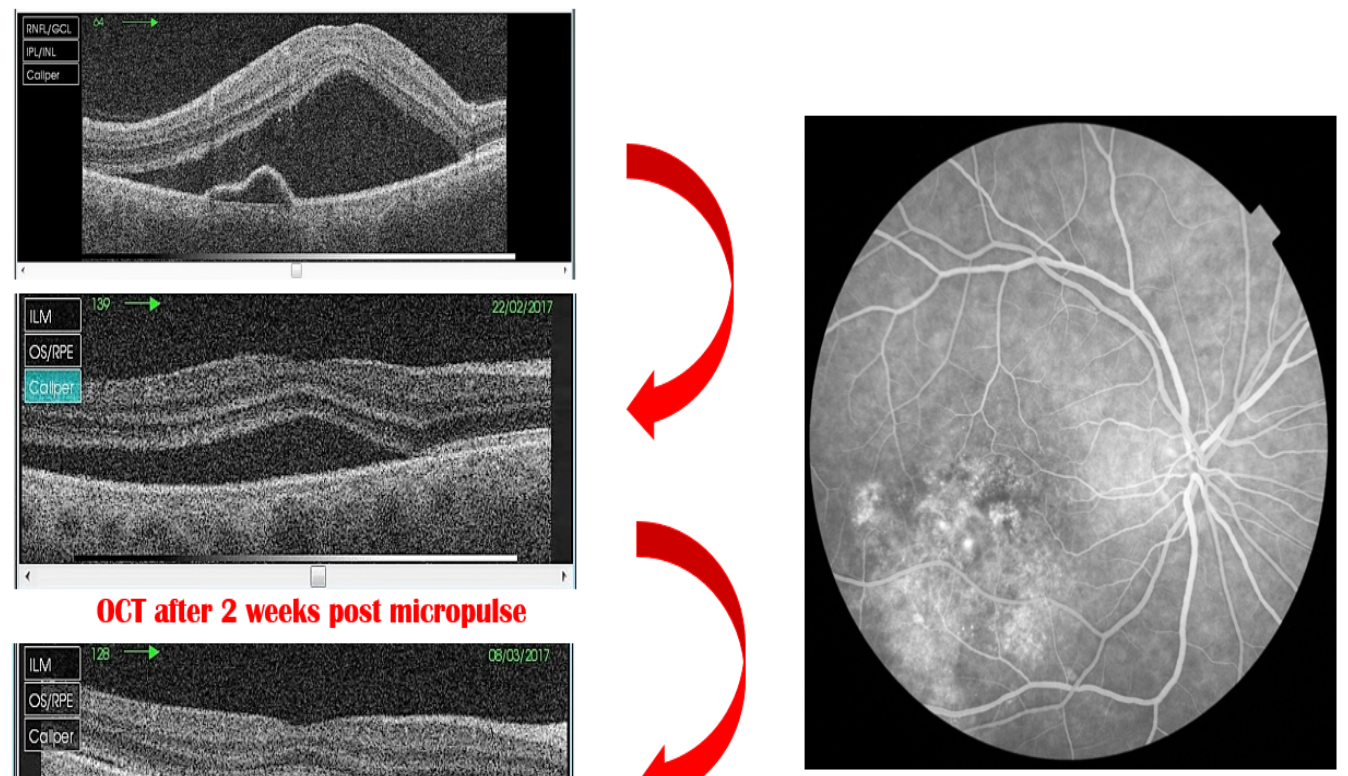

FA in the late phase showed multiple leakage areas near fovea
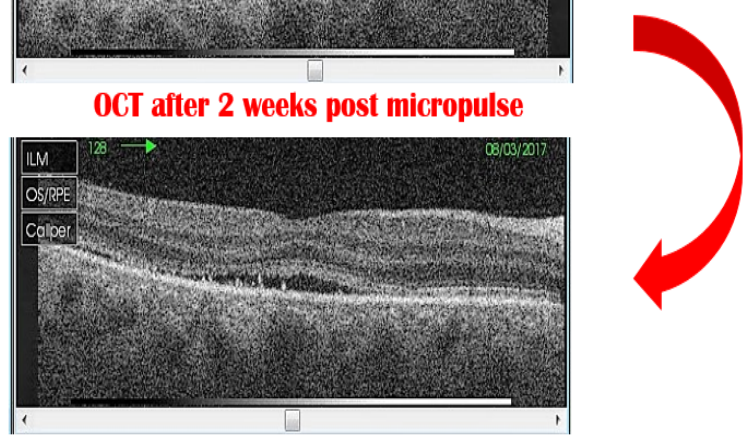

OCT after 4 weeks post micropulse

Figure 1. We treated this patient with Micropulse settings on the Iridex IQ 532 laser: 200 um spot, $300 \mathrm{~mW}, 15 \%$ duty cycle, 98 shots at 300 miliseconds. After 2 weeks the vision had improved to $(20 / 80)$ and at the 4 th week post micropulse laser, the vision had reached to $(20 / 30)$
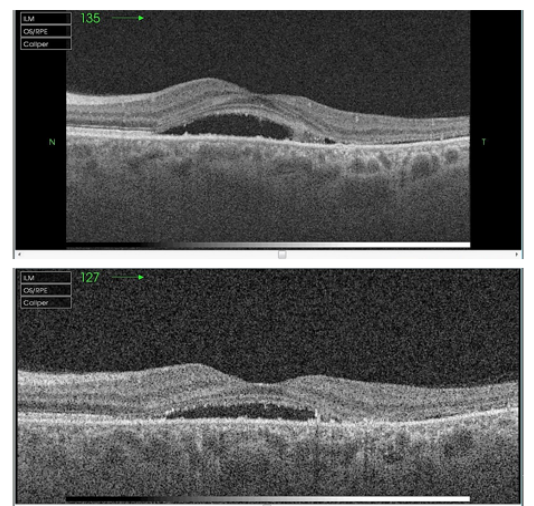

OCT after 2 weeks post micropulse

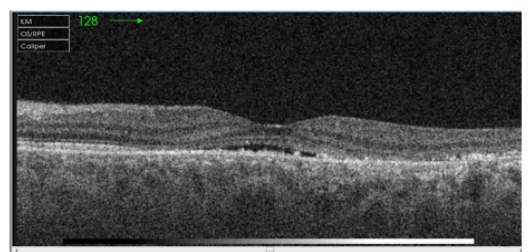

OCT after 4 weeks post micropulse
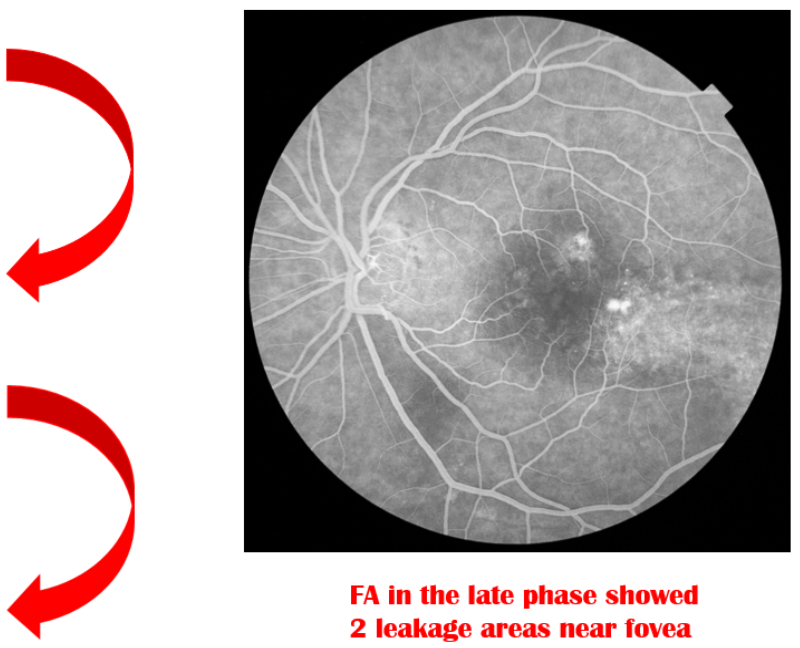

FA in the late phase showed

2 leakage areas near fovea

Figure 2. We treated this patient with Micropulse settings on the Iridex IQ 532 laser: 200 um spot, $200 \mathrm{~mW}, 15 \%$ duty cycle, 98 shots at 300 miliseconds. After 2 weeks the vision had improved to $(20 / 50)$ and at the 4 th week post micropulse laser, the vision had reached to $(20 / 25)$

\section{Case 2}

32 year old female, had a history of reduced visual acuity in the left eye (20/100) of 6 months duration, the patient was treated with 3 intravitreal injections of aflibercept (Eylea, Bayer) in the left eye with no improvement. Angiogram showed 2 leakage areas near fovea of the left eye and the OCT showed subfoveal neurosensory detachment (Figure 2).

\section{Discussion}

Chronic CSCR can result in permanent vision loss with extensive RPE changes. Observation and anti-VEGFs are not always the only treatment option, and are not the best option in many cases. 
MicroPulse laser is a noninvasive procedure, it has a tissue-sparing effect, and there is no thermal damage. It can also be repeated after 3 to 6 months, without fear of damaging the inner retina. Prof. Dr. Sascha Fauser (head physician of the department for vitreoretinal surgery at the University Eye Hospital of Cologne), did a clinical study that included 38 patients ,comparing micropulse laser and half dose PDT treatment options in chronic CSCR. At last follow-up (about 5 months posttreatment), $24 \%$ were dry, $50 \%$ showed some improvement, and $26 \%$ had no change. He found that the patients with chronic CSR responded quickly to micropulse laser treatment.

\section{Conclusion}

This trail small cases review provides that micropulse laser treatment is a good option for treatment of chronic non resolving cases of CSR especially those cases that not responding to multiple anti VEGF injections. Micropulse laser enables treatment to leakage areas close to the fovea with high safety than conventional laser and PDT. We need a more new studies in future so that long term results can be analyzed.

\section{Conflict of interest}

No conflict of interest

\section{References}

1. Clinical Ophthalmology: A Systematic Approach, 7th Edition, by Jack J. Kanski, MD, MS, FRCS, FRCOphth and Brad Bowling, FRCSEd(Ophth), FRCOphth.

2. Wang M1, Munch IC, Hasler PW, Prünte C, Larsen M (2008) Central serous chorioretinopathy. Acta Ophthalmol 86: 126-145. [Crossref]

3. Koss MJ1, Beger I, Koch FH (2012) Subthreshold diode laser micropulse photocoagulation versus intravitreal injections of bevacizumab in the treatment of central serous chorioretinopathy. Eye (Lond) 26: 307-314. [Crossref]

4. Kitzmann AS1, Pulido JS, Diehl NN, Hodge DO, Burke JP (2008) The incidence of central serous chorioretinopathy in Olmsted County, Minnesota, 1980-2002. Ophthalmology 115: 169-173. [Crossref]
5. Gass JD (1967) Pathogenesis of disciform detachment of the neuroepithelium. Am J Ophthalmol 63: Suppl:1-139. [Crossref]

6. Ross A1, Ross AH, Mohamed Q (2011) Review and update of central serous chorioretinopathy. Curr Opin Ophthalmol 22: 166-173. [Crossref]

7. André maia (2010) Retina Today, A New Treatment for Chronic Central Serous Retinopathy.

8. Lanzetta P, Furlan F, Morgante L, Veritti D, Bandello F (2008) Nonvisible subthreshold micropulse diode laser $(810 \mathrm{~nm})$ treatment of central serous chorioretinopathy: A pilot study. Eur J Ophthalmol 18: 934-40. [Crossref]

9. Chen SN1, Hwang JF, Tseng LF, Lin CJ (2008) Subthreshold diode micropulse photocoagulation for the treatment of chronic central serous chorioretinopathy with juxtafoveal leakage. Ophthalmology 115: 2229-2234. [Crossref]

10. Koss MJ, Beger I, Koch FH (2012) Subthreshold diode laser micropulse photocoagulation versus intravitreal injections of bevacizumab in the treatment of central serous chorioretinopathy. Eye (Lond) 26(2): 307-314. [Crossref]

11. Ficker L, Vafidis G, While A, Leaver P (1988) Longterm follow-up of a prospective trial of argon laser photocoagulation in the treatment of central serous retinopathy. $\mathrm{Br}$ Ophthalmol 72: 829-834. [Crossref]

12. Lai TY, Chan W-M, Lam DS (2004) Transient reductionin retinal function revealed by multifocal electroretinogram after photodynamictherapy. Am J Ophthalmol 137: 826-833. [Crossref]

13. Sivaprasad S1, Elagouz M, McHugh D, Shona O, Dorin G (2010) Micropulsed diode laser therapy: evolution and clinical applications. Surv Ophthalmol 55: 516-530. [Crossref]

14. Wang MS1, Sander B, Larsen M (2002) Retinal atrophy in idiopathic central serous chorioretinopathy. Am J Ophthalmol 133: 787-793. [Crossref]

15. Lavinsky D, Palanker D (2015) Nondamaging photothermal therapy for the retina: initial clinical experience with chronic central serous retinopathy. Retina 35:213-222. [Crossref]

16. Yadav N, Jayadev C, Mohan A, Vijayan P, Battu R, et al. (2015) Subthreshold micropulse yellow laser $(577 \mathrm{~nm})$ in chronic central serous chorioretinopathy:safety profile and treatment outcome. Eye (Lond) 29:258-26. [Crossref]

Copyright: (C2017 Mamoori FA. This is an open-access article distributed under the terms of the Creative Commons Attribution License, which permits unrestricted use, distribution, and reproduction in any medium, provided the original author and source are credited. 